Article

\title{
Who Uses Right-Wing Alternative Online Media? An Exploration of Audience Characteristics
}

\author{
Heidi Schulze \\ GESIS—Leibniz Institute for the Social Sciences, 50667 Cologne, Germany; E-Mail: heidi.schulze@gesis.org
}

Submitted: 15 February 2020 | Accepted: 10 June 2020 | Published: 17 July 2020

\begin{abstract}
Accompanying the success of the radical right and right-wing populist movements, right-wing alternative online media have recently gained prominence and, to some extent, influence on public discourse and elections. The existing scholarship so far focuses primarily on the role of content and social media distribution and pays little attention to the audiences of rightwing alternative media, especially at a cross-national level and in the European context. The present paper addresses this gap by exploring the characteristics of the audiences of right-wing alternative online media. Based on a secondary data analysis of the 2019 Reuters Digital News Survey, this article presents a cross-national analysis of right-wing alternative media use in Northern and Central Europe. The results indicate a comparatively high prevalence of right-wing alternative online media in Sweden, whereas in Germany, Austria, and Finland, these news websites seem to be far less popular. With regard to audience characteristics, the strongest predictors of right-wing alternative online media use are political interest and a critical stance towards immigration, accompanied by a skeptical assessment of news quality, in general, and distrust, especially in public service broadcasting media. Additionally, the use of social media as a primary news source increases the likelihood of right-wing alternative news consumption. This corroborates the high relevance of social media platforms as distributors and multipliers of right-wing alternative news content. The findings suggest that right-wing alternative online media should not be underestimated as a peripheral phenomenon, but rather have to be considered influential factors for center-right to radical right-leaning politics and audiences in public discourse, with a high mobilizing and polarizing potential.
\end{abstract}

\section{Keywords}

alternative online media; hyperpartisan media; immigration-critical; news distrust; populist communication; right-wing media; right-wing populist

Issue

This article is part of the issue "Populism and Polarization: A Dual Threat to Europe's Liberal Democracies?" edited by Jonas Linde (University of Bergen, Norway), Marlene Mauk (GESIS - Leibniz Institute for the Social Sciences, Germany) and Heidi Schulze (GESIS-Leibniz Institute for the Social Sciences, Germany).

(C) 2020 by the author; licensee Cogitatio (Lisbon, Portugal). This article is licensed under a Creative Commons Attribution 4.0 International License (CC BY).

\section{Introduction}

The first right-wing alternative news websites appeared as early as the mid-1990s (Conway, Scrivens, \& Macnair, 2019). Thus, the phenomenon of so-called right-wing alternative online media, also referred to as hyperpartisan media, is not new. However, in the past decadeaccompanying, and possibly fueling - the rise of rightwing populists (Müller \& Schulz, 2019), nationalism (Marwick \& Lewis, 2017), islamophobia (Puschmann, Ausserhofer, Maan, \& Hametner, 2016), political po- larization (Tucker et al., 2018), and right-wing alternative online media started to gain prominence and, to some extent, influence on public discourse (Benkler, Faris, \& Roberts, 2018). By successfully tapping into the opportunity structures of the Internet, these media websites are believed to disseminate conspiracy theories and pseudoscience (Starbird, 2017), propagate authoritarian and anti-immigration attitudes (Haller, 2018; von Nordheim, Müller, \& Scheppe, 2019), as well as foster distrust in elites, traditional media, and society (Figenschou \& Ihlebæk, 2018; Schindler, Fortkord, 
Posthumus, Obermaier, \& Reinemann, 2018). The latest since the rise of Breitbart News during the 2016 US Elections, there is a burgeoning scholarship in the US context. However, in the European context, empiricalparticularly quantitative-studies on these right-wing news sources are still scarce compared to the research concerned with right-wing populism and the radical right. Despite this, a quickly growing body of research indicates a high relevance of right-wing alternative online media in Central and Northern Europe. The overarching majority of the studies present country-specific analyses of the content, content production, or social media presence of right-wing alternative online media for countries such as Sweden (de La Brosse \& Thinsz, 2019; Sandberg \& Ihlebaek, 2019), Germany (Frischlich, Klapproth, \& Brinkschulte, 2020; von Nordheim et al., 2019) and Finland (Noppari, Hiltunen, \& Ahva, 2019; Ylä-Anttila, 2018). Studies focusing on the audiences of right-wing alternative media, as well as cross-national research design, however, are still rare. In one of these few studies, Heft, Mayerhöffer, Reinhardt, and Knüpfer (2019) presented one of the first cross-national analyses concerning the content of right-wing news websites across Austria, Denmark, Germany, Sweden, the UK, and the US. In another such study, Nygaard (2020) compared intermedia agenda setting in right-wing alternative and traditional online news in Norway, Sweden, and Denmark. Considering the societal relevance of the phenomenon, it is necessary to further improve our understanding of right-wing alternative online media, specifically, their audiences (Rauch, 2019).

This article contributes to the scholarship by looking into the audiences of right-wing alternative news media online in Northern and Central Europe. Specifically, this research seeks to understand the prevalence of rightwing alternative online news media use in Northern and Central Europe and the audience characteristics that predict the use of such media. Based on data from the 2019 Reuters Digital News survey (Newman, Fletcher, Kalogeropoulos, \& Nielsen, 2019), this article examines these topics within the context of Austria, Finland, Germany, and Sweden. By following a cross-national approach, the study aims to provide a broader and more generalizable understanding of right-wing alternative online media. The results indicate a comparatively high prevalence of right-wing alternative news in Sweden; in contrast, in Germany, Austria, and Finland, these news websites seem to be far less popular. Additionally, the results indicate that the strongest predictors of right-wing alternative online news use are political interest, a critical stance towards immigration, the relevance of social media as a news source, as well as skeptical assessment of news in general and distrust, especially, in public service broadcasting media.

In the next section, the concepts forming the basis of the study are presented: First, the terminological difficulties in right-wing alternative online media are addressed; next, possible predictors of right-wing alternative media use are discussed on the grounds of previous research. Thereafter, in the section that follows, the methodological approach as well as the operationalization are described. Finally, the results are presented and discussed in the last two sections.

\section{Right-Wing Alternative Online Media: Conceptualizations and Audiences}

Overall, "little attention has been paid to right-wing media as alternative media" (Atton, 2006, p. 574). This quote is still valid today, and despite the seemingly increasing relevance of alternative media channels, further research on the changing role of these channels is necessary (Holt, Ustad Figenschou, \& Frischlich, 2019). In addition, there is a terminological debate within the scholarship of the originary rather left-wing alternative media, about whether right-wing and, especially, far-right alternative media actually can be called alternative media (Rauch, 2019).

\subsection{Conceptual and Terminological Obscurity}

Currently, there is no generally agreed upon term or definition of right-wing alternative online media (Haller, Holt, \& de La Brosse, 2019). Holt (2018, p. 2) argues "that some of this confusion, at least in terms of scholarly attempts to come to grips with it, has to do with a discrepancy between the dominant theories about alternative media and alternative media as they actually are." In other words, there is a gap between the traditional scholarship of alternative media and the newly relevant media channels, such as Breitbart and Co., that could potentially also be studied as alternative media.

Alternative media need always be discussed as a reflection of society, since they are a result of the cultural and, thus, temporal environment of society. This means the attribute 'alternative' might be subject to change over time. For example, the German newspaper taz evolved as an alternative medium in the 1970s and was still studied as such in the 1990s (Mathes \& Pfetsch, 1991); in contrast, today, it is considered to be a part of the traditional news media sphere with a left-wing bias. Similarly, The Huffington Post could, in its initial phase, be studied as an alternative online medium, whereas today, it is an internationally relevant news website that employs professional journalists. This shows that it is vital to view the relationship between traditional news media and alternative online media as a continuous scale, on which each individual outlet may be positioned with respect to its current status.

As a further consequence of the conceptual debate, there are a plethora of terms employed to describe right-wing alternative online media, e.g., far-right media (Rauch, 2019), anti-elitist alternative media (Müller \& Schulz, 2019), and populist alternative media (Holt \& Haller, 2017). However, it is not always clear whether or not they refer to the same phenomenon. Some termino- 
logical differences are rooted in minor conceptual differences. For instance, von Nordheim et al. (2019) differentiate between reactive and autonomous media, that is, between media that simply react and comment on traditional media content and those that genuinely operate on their own topical agenda. There are also countryspecific differences: For example, in Sweden, the term immigration-critical alternative media (Nygaard, 2019) is preferred, whereas, in Finland, right-wing alternative news websites are referred to as populist countermedia websites (Noppari et al., 2019). It can be assumed that, to some extent, these terms were created to circumvent the term right-wing alternative media on account of the open terminological debate about its use. However, the applicability of these more specific terms remains under debate in the absence of further contentspecific analyses.

After a broader discussion of different aspects of (right-wing) alternative online media, Holt et al. (2019, p. 3) proposed an overarching definition in favor of the concept of alternative media: "Alternative news media represent a proclaimed and/or (self) perceived corrective, opposing the overall tendency of public discourse emanating from what is perceived as the dominant mainstream media in a given system." In light of the conceptual difficulties concerning right-wing alternative online media, this paper has adopted this general conceptualization.

\subsection{Audiences of Right-Wing Alternative Online Media}

Right-wing alternative media are, compared to traditional news media, rather small with respect to their reach. Still, some audiences consider them relevant news sources because alternative media present niche topics, voices, and opinions that are not covered by traditional news media (Rauch, 2015). In particular, in the wake of recent societal crises, such as the financial crisis and the refugee crisis, the relevance of right-wing alternative media has been growing in Europe (Haller et al., 2019). Thus, alternative online media receive a certain share of audience. It is unclear, though, how many people (approximately) are aware of or follow rightwing alternative news websites, and how these numbers vary across countries in Europe. Consequently, Research Question 1 is:

RQ 1: How prevalent are right-wing alternative online media in Northern and Central Europe?

To increase the understanding and discussion of the prevalence, it is necessary to study the audiences of right-wing alternative news websites and their characteristics. Most audience-related research so far either studied audiences of rather left-leaning, activist alternative media audiences (e.g., Downing, 2003; Rauch, 2007), audience engagement with social media accounts of right-wing media (e.g., Larsson, 2019; Sandberg \&
Ihlebaek, 2019), or characteristics of populist audiences (e.g., Fawzi, 2019; Schulz, 2019). A few, very recent publications study the audiences of right-wing alternative online media, however, only on the basis of single-country analyses (Müller \& Schulz, 2019; Noppari et al., 2019; Rauch, 2019). The link and "the interactions between right-wing alternative media and their audiences require urgent examination" (Rauch, 2019, p. 34). Therefore, the main topic of interest of this study is the individual-level characteristics that predict right-wing alternative online media consumption across Northern and Central Europe. It has been shown that in these areas, specifically, the rise of right-wing populist parties was accompanied by an increase in right-wing alternative news websites and their contents (Bachl, 2018; Holt, 2019; Ylä-Anttila, 2018). Thus, the second research question is as follows:

RQ2: Which recipient characteristics predict the use of right-wing alternative online media?

Below, potentially relevant characteristics are discussed on the basis of previous research concerning the audiences, as well as the conceptualizations of rightwing alternative news websites. The discussion of the audience characteristics is organized with regard to three dimensions: political and populist, news use, and news assessment.

\subsubsection{Political and Populist}

In general, political interest is a relevant predictor of news consumption (Strömbäck, Djerf-Pierre, \& Shehata, 2013). More precisely, Tsfati and Cappella (2003) showed that political interest is associated with both, traditional and nonmainstream, news use. Therefore, it is assumed that an interest in politics is a basic prerequisite for the use of alternative news media, since they predominantly present and discuss political news. This leads to the first hypothesis:

H1a: Political interest is associated with a higher likelihood of right-wing alternative online media use.

The hybrid media structure of the Internet offers an ideal foundation for the populist communication logic, and the scholarship of populist communication has considered alternative online media as relevant distribution channels for populist messages (Engesser, Fawzi, \& Larsson, 2017). However, at present, there is relatively little evidence on how far right-wing populist politicians actively employ alternative media for their cause. Bachl (2018) analyzed media sources shared on the Facebook pages of Germany's right-wing populist party and found a high level of presence of channels linked to the right-wing alternative media sphere. Müller and Schulz (2019) differentiated between occasional and frequent alternative news use and found that populist attitudes linked to right-wing ideology increase the probability of reg- 
ular right-wing alternative news use. Similarly, Stier, Kirkizh, Froio, and Schroeder (2020) showed that people with populist attitudes consume alternative news media more frequently. This is reflected in the next hypothesis.

H1b: Support of right-wing populist topics and attitudes is associated with a higher likelihood of rightwing alternative online media use.

Accordingly, based on the selective exposure theory, it can be assumed that proponents of right-wing populist ideas prefer media channels that support their beliefs (and provide attitude-consistent information) over those that challenge them and, thus, preferably follow rightwing alternative media that present familiar interpretive schemes (Hart et al., 2009). Based on news users' preference for attitude-consistent information, it is expected that the users of right-wing alternative news websites would also exhibit right-wing attitudes, as stated in the following hypothesis.

H1c: Political right-wing orientation is associated with a higher likelihood of right-wing alternative online media use.

\subsubsection{News Use}

An analysis of the news media repertoires of right-wing alternative news users indicated a comprehensive news diet, specifically with respect to online news sources (Schulze \& Hölig, 2020). Therefore, considering that the content of right-wing alternative media is usually focused primarily on political news (Holt, 2017), it is assumed that a general interest in the news is an essential prerequisite for interest in alternative news media and their content. Thus, similar to the hypothesis on the role of political interest, the following hypothesis focuses on the role of news interest.

H2a: News interest and, thus, news use frequency is associated with a higher likelihood of right-wing alternative online media use.

Simultaneously, it can be assumed that right-wing alternative news users turn to alternative news, in order to avoid traditional news content that does not align with and represent their political beliefs or topics of interest. Intentional news avoidance as an assumption of selective exposure theory is empirically more complex and more contested than the assumption of attitude-consistent information-seeking (Garrett, 2009). However, several studies showed that right-wing audiences, in particular, prefer and build ideologically aligned media repertoires by intentionally avoiding opposing news sources (Benkler et al., 2018; Rauch, 2019). Thus, while highly interested in political news, audiences of right-wing alternative media employ right-wing alternative media as an alternative news source actively, which allows them to actively avoid traditional news sources. This forms our next hypothesis.

$\mathrm{H} 2 \mathrm{~b}$ : News avoidance is associated with a higher likelihood of right-wing alternative online media use.

Social media use, and especially Facebook and Twitter use, was found to increase the probability of rightwing alternative news consumption (Müller \& Schulz, 2019). Further, a comparison of audience engagement among followers of alternative and traditional news on social media showed that alternative news audiences are more active with respect to their commenting and liking behaviors as well as the distribution of contents to their followers (Larsson, 2019; Sandberg \& Ihlebaek, 2019). Alternative media efficiently use social media to distribute their content to audiences who, otherwise, would not come in contact with it. Consequently, people who use social media as a (primary) source of news might have a higher probability of being exposed to different online news sources, including alternative news, as explained in the next hypothesis.

H2c: Use of social media as the main news source, as well as the use of social media channels to access news, is associated with a higher likelihood of rightwing alternative online media use.

\subsubsection{Skepticism and Distrust}

One feature that all alternative media "have...in common: The people who are moved to produce and access such media tend to feel that their interests, perspectives, communities, and indeed their very selves are (at best) inadequately represented within most mainstream media" (Harcup, 2016, p. 20). Similarly, Holt et al. (2019) argue that the overarching characteristic of alternative online media is their (self-) perceived corrective. That is, alternative media are critical of the general public discourse, and this is reflected in their critical stance towards traditional media, which are perceived as the main driver of the general public discourse. This is frequently accompanied by skepticism towards, and may sometimes even result in distrust in, traditional media, depending on the specific news medium (Holt, 2018). Accordingly, Tsfati and Cappella (2003, p. 504) showed that "media skepticism is negatively associated with mainstream news exposure but positively associated with nonmainstream news exposure." This is summed up in the next hypothesis.

$\mathrm{H} 3 \mathrm{a}$ : The tendency to critically assess traditional news media is associated with a higher likelihood of rightwing alternative online media use.

With regard to the link between trust and media consumption, several studies show that trust in news media and alternative news consumption are negatively corre- 
lated. Followers of alternative media, generally, show a lower level of trust in news and traditional media (Tsfati \& Peri, 2006), and people with such low trust levels often prefer alternative news sources (Fletcher \& Park, 2017). Distrust in media seems to be exceptionally high in politically extreme people; that is, it seems to be higher in people who expressively lean left or right (Otto \& Köhler, 2016).

$\mathrm{H} 3 \mathrm{~b}$ : Trust in news media, in general, is negatively associated with right-wing alternative online media use.

However, contrary to previous research, Kalogeropoulos, Suiter, Udris, and Eisenegger (2019) found that alternative news use was positively correlated with trust in the news. Specifically, a low level of trust was only observed in respondents who also used social media as the primary news source. This means that the concept of distrust in right-wing alternative online media users needs to be understood at a finer level. In addition to their support of right-wing populist ideas, it is expected that alternative news users distrust not only legacy news media but also public service broadcasting news (PSB), of which they are highly critical, since they perceive these media as an extension of the general public discourse as well as a biased loudspeaker for elite opinions that they oppose (Noppari et al., 2019; Rauch, 2019). In contrast, it has been shown that populist audiences frequently consume tabloid news (Fawzi, 2019; Schulz, 2019) and that some right-wing alternative websites strategically mimic tabloid news styles (Farkas \& Neumayer, 2020). Hence, we assume a positive association between trust in tabloid news and right-wing alternative news consumption.

H3c: Trust in PSB and legacy news is negatively associated, whereas trust in tabloid news is positively associated with right-wing alternative online media use.

\section{Method}

A secondary data analysis of the 2019 Reuters Digital News Survey was performed to explore the questions and hypotheses of the present study. The Reuters Digital News Survey (Newman et al., 2019) is a cross-sectional online survey, supervised by the Reuters Institute for the Study of Journalism, which aims at gathering data on me- dia and news consumption behavior. Sampling is carried out at the country level by using representative quotas for the variables gender, age, education, and region. In addition, the data are weighted according to the census. Due to the method used for data collection, people who never or hardly ever use the Internet are underrepresented. The results are, therefore, representative of all Internet users of a country who use the Internet at least once a month.

In 2019, the survey was conducted in 38 countries in the period January to February 2019. This study follows a cross-national approach that provides a broader understanding of right-wing alternative news consumption. The questionnaire differs between countries: (1) In some countries, the alternative news websites chosen for the survey show certain country-specific peculiarities and thus, comparison across these countries is difficult. (2) In some other countries, for example, Denmark and Switzerland, the surveys do not include questions that are relevant for this study. As a result of these limitations and the conceptual difficulties discussed in Section 2, this study focuses on countries that are structurally similar and for which the surveyed alternative news media can be compared to ensure equivalence. Accordingly, the countries chosen for analysis are Germany, Austria, Sweden, and Finland. In all of these countries, rightwing alternative news websites seem to be of high relevance, accompanied by the electoral successes of rightwing populist parties (Fletcher, 2019). In addition, albeit minor structural differences, these four countries share many characteristics and belong to the same media system type, namely, the democratic corporatist model (Hallin \& Mancini, 2004). Their similarities include, for example, strong public-service broadcasting systems, high numbers of newspaper circulation, as well as a high degree of professionalization of the newspaper markets. Furthermore, a recent empirical re-characterization of the media system typology has introduced a northern media type (represented by Sweden and Finland) and a central media type (represented by Germany and Austria; Brüggemann, Engesser, Büchel, Humprecht, \& Castro, 2014).

With regard to the Reuters data, the sample sizes are similarly large, and the samples for these four countries are rather similar in terms of the sociodemographic variables gender and age (see Table 1).

Table 1. Sample overview per country.

\begin{tabular}{llll}
\hline Country & $\mathrm{N}$ & Gender & Age \\
\hline Austria & $\mathrm{N}=2010$ & $\mathrm{~m}=48.5 \% \mathrm{f}=51.5 \%$ & $\mathrm{M}=47.8(\mathrm{SD}=15.9)$ \\
Germany & $\mathrm{N}=2022$ & $\mathrm{~m}=48.6 \% \mathrm{f}=51.4 \%$ & $\mathrm{M}=48.3(\mathrm{SD}=15.8)$ \\
Finland & $\mathrm{N}=2009$ & $\mathrm{~m}=48.8 \% \mathrm{f}=51.2 \%$ & $\mathrm{M}=48.3(\mathrm{SD}=16.6)$ \\
Sweden & $\mathrm{N}=2007$ & $\mathrm{~m}=49.8 \% \mathrm{f}=50.2 \%$ & $\mathrm{M}=48.8(\mathrm{SD}=17.5)$ \\
Total & $\mathrm{N}=8048$ & $\mathrm{~m}=48.9 \% \mathrm{f}=51.1 \%$ & $\mathrm{M}=48.3(\mathrm{SD}=16.5)$ \\
\hline
\end{tabular}

Notes: The numbers are weighted. Source: Newman et al. (2019). 


\subsection{Dependent Variable: Usage of Right-Wing Alternative Online Media}

For data on the dependent variable, usage of right-wing alternative online media, respondents were asked for a list of news websites that they had (1) heard of and (2) had used to access news in the last week. Only alternative news websites to which a right-wing bias could be attributed were included in the analysis. The bias attribution was based on previous studies, such as for Germany (Bachl, 2018; Müller \& Schulz, 2019; Puschmann et al., 2016), Austria (Heft et al., 2019; Newman, Fletcher, Kalogeropulos, Levy, \& Nielsen, 2018), Sweden (Heft et al., 2019; Holt, 2019; Sandberg \& Ihlebaek, 2019), and Finland (Noppari et al., 2019; Ylä-Anttila, 2018).

Table 2 presents a country-specific overview of all alternative news websites, including the number of respondents who stated they had used each medium. The dependent variable right-wing alternative online media usage was created by aggregating the responses to the media use question and recoding it into a binary variable. The variable thus derived indicates, for each respondent, whether the person had used at least one of the websites listed in Table 2 during the past week or not.

The subsequent sections describe the operationalization of the individual-level predictor variables.

\subsection{Predictors: Political and Populist}

For the evaluation of political interest as a predictor of right-wing alternative online media use, the respondents were asked to rate three variables as measures of the level of support for right-wing populist attitudes. They rated the following three variables on a five-point Likert scale (single item) ranging from 'strongly disagree' to 'strongly agree': (1) immigration-critical (the corresponding statement was 'Immigration threatens our national culture'), (2) external efficacy (the corresponding statement was 'Most elected officials don't care what people like me think'), and (3) support of direct democracy

Table 2. Overview of usage of right-wing alternative media websites.

\begin{tabular}{|c|c|c|c|c|}
\hline Country & Medium & Website & Social Media Accounts & Number of Users (in \%) \\
\hline \multicolumn{5}{|l|}{ Austria } \\
\hline & Unzensuriert & unzensuriert.at & YouTube, Facebook, Twitter, VK & $81(4.0)$ \\
\hline & Info Direkt & Info-direkt.eu & $\begin{array}{l}\text { YouTube, Facebook, Instagram, } \\
\text { Twitter, VK }\end{array}$ & $41(2.0)$ \\
\hline & Alles Roger? & www.allesroger.at & Facebook & $32(1.6)$ \\
\hline & Contra Magazin & Contra-magazin.com & YouTube, Facebook, Twitter, VK & $31(1.5)$ \\
\hline \multicolumn{5}{|l|}{ Finland } \\
\hline & MV-Lehti & mvlehti.net & Facebook, VK & $80(4.0)$ \\
\hline & Nykysuomi & nykysuomi.com & Youtube, Facebook, Twitter, VK & $47(2.3)$ \\
\hline & Kansalainen & kansalainen.fi & YouTube, Facebook, Twitter & $44(2.2)$ \\
\hline & Magneettimedia & magneettimedia.com & YouTube, Facebook, Instagram & $30(1.5)$ \\
\hline & Oikea Media & oikeamedia.com & YouTube, Facebook,Twitter & $30(1.5)$ \\
\hline \multicolumn{5}{|l|}{ Germany } \\
\hline & Junge Freiheit & jungefreiheit.de & $\begin{array}{l}\text { YouTube, Facebook, Instagram, } \\
\text { Twitter, Pinterest }\end{array}$ & $63(3.1)$ \\
\hline & RT Deutsch & deutsch.rt.com & $\begin{array}{l}\text { YouTube, Facebook, Instagram, } \\
\text { Twitter, VK }\end{array}$ & $58(2.9)$ \\
\hline & Compact Online & compact-online.de & $\begin{array}{l}\text { YouTube, Facebook, Instagram, } \\
\text { Twitter, VK }\end{array}$ & $51(2.6)$ \\
\hline & Epoch Times & epochtimes.de & $\begin{array}{l}\text { YouTube, Facebook, Instagram, } \\
\text { Twitter, VK }\end{array}$ & $41(2.0)$ \\
\hline & Politically Incorrect & pi-news.net & YouTube, Facebook, Twitter, VK & $39(1.93)$ \\
\hline \multicolumn{5}{|l|}{ Sweden } \\
\hline & Nyheter Idag & nyheteridag.se & YouTube, Facebook, Twitter & $216(10.7)$ \\
\hline & Fria Tider & www.friatider.se & YouTube, Facebook, Twitter & $205(10.2)$ \\
\hline & Samhällsnytt & samnytt.se & YouTube, Facebook, Instagram, VK & $175(8.7)$ \\
\hline & Ledarsidorna & ledarsidorna.se & YouTube, Facebook, Twitter & $146(7.2)$ \\
\hline & Samtiden & samtiden.nu & YouTube & $120(6.0)$ \\
\hline & Nya tider & nyatider.nu & $\begin{array}{l}\text { YouTube, Facebook, Instagram, } \\
\text { Twitter }\end{array}$ & $119(5.9)$ \\
\hline & Det goda samhället & detgodasamhallet.com & Facebook, Twitter & $77(3.8)$ \\
\hline
\end{tabular}

Notes: The numbers are weighted. Source: Newman et al. (2019). 
(the corresponding statement was 'The people should be asked whenever important decisions are taken'). The third variable is based on the notion of the sovereignty of the will of the people (Fletcher, 2019).

The degree to which respondents can be considered to be politically right-leaning (slightly, fairly, or very rightwing) was based on their self-placement on a six-point scale ranging across 'very left-wing,' 'center,' and 'very right-wing.'

\subsection{Predictors: News Consumption}

The variable news use frequency was rated on a ten-point scale ranging from 'never' to 'more than ten times a day.' News interest was rated on a five-point scale from 'not at all interested' to 'extremely interested.' For the variable news avoidance, respondents were asked whether they were actively trying to avoid news (with the options being 'often, sometimes, occasionally, never'). The variable social media for news represents a count aggregate of all social media channels a respondent had claimed to use for news. The main news source was determined from a list of eleven different news sources, including the items 'social media' and 'blogs,' which were used to create the binary variable social media as the main news source.

\subsection{Predictors: News Assessment}

News skepticism comprised four different items that were rated on a five-point Likert scale ('strongly disagree' to 'strongly agree') and aggregated (slightly different for each country, Cronbach's $\alpha$ ranged from 0.7 to 0.8 ). Of the four items, the first three items were reversed to match the direction of the variable: (1) 'news media monitor and scrutinize powerful people and businesses,'
(2) 'news media keep me up to date about what's going on,' (3) 'news media help me understand the news of the day,' and (4) 'topics chosen by the news media do not feel relevant to me.'

The overall stance towards the traditional news media within a country, indicated by the variable trust in news, was based on the respondents' response to how much they trusted the news as a whole within their country (with the responses ranging from 'strongly disagree' to 'strongly agree'). To discuss the (lack of) trust in greater detail, the variables trust PSB, trust tabloid, and trust legacy were included as predictors. These variables were recoded for each country individually, based on the respondents' ratings of the trustworthiness of a list of several news media on a ten-point scale ranging from 'not at all trustworthy' to 'completely trustworthy.'

\section{Results}

\subsection{Prevalence of Right-Wing Alternative Online Media}

Overall, there were a total of 8048 respondents from Germany, Austria, Sweden, and Finland. However, only 931 (11.6\%) reported having accessed the websites listed in Table 2 to use news within the past seven days. Of these, the overarching majority $(576 / 931,61.9 \%)$ had accessed only one of the listed channels, and merely $355(4.4 \%)$ respondents had visited two or more of these websites within the past week.

Figure 1 presents the country-specific prevalence of right-wing alternative online media use in terms of the percentage of respondents who had either heard of (Awareness) and/or accessed (Usage) these media. With regard to usage, Sweden stands out: While the share of users is relatively similar (8\%) across Austria,

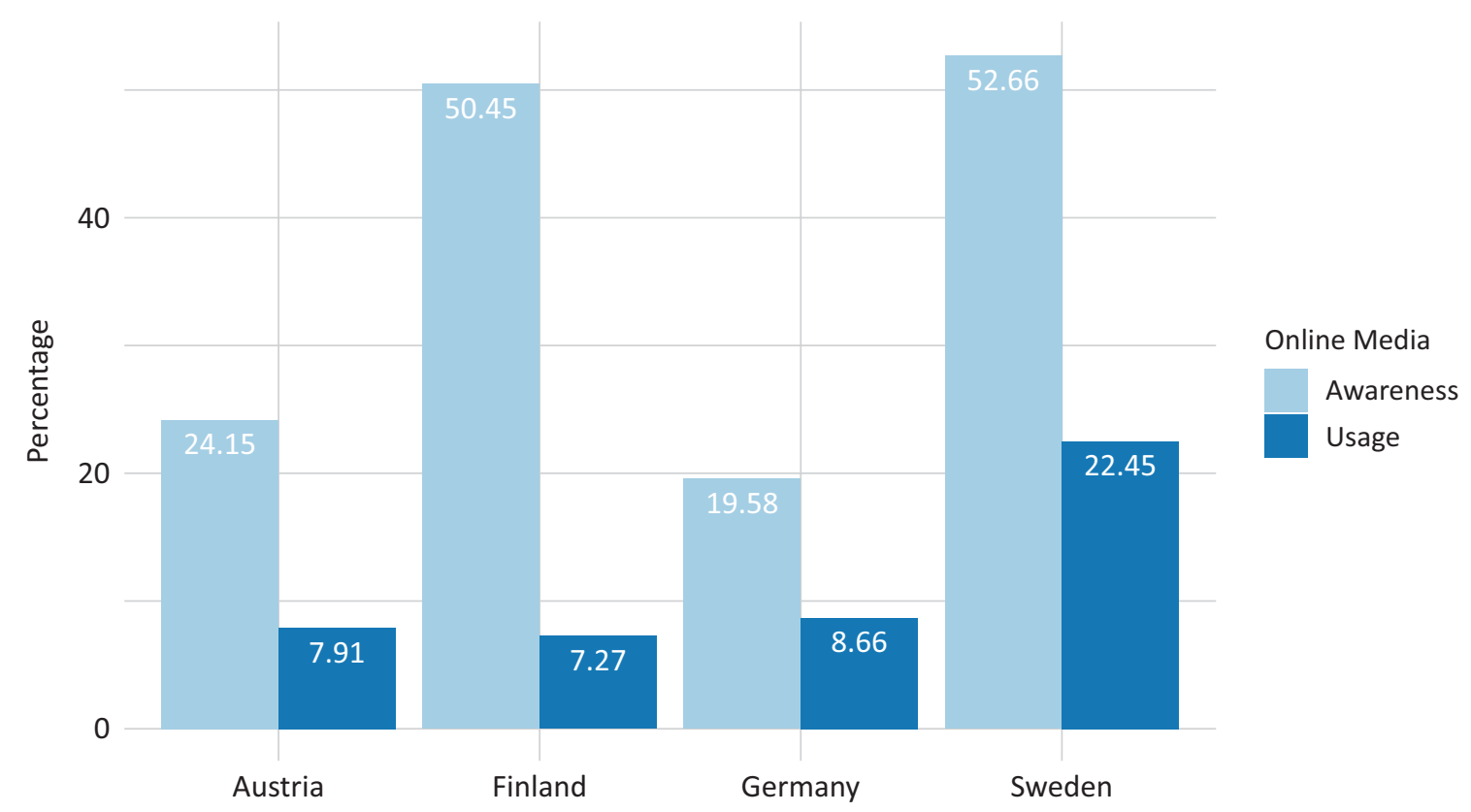

Figure 1. Prevalence of right-wing alternative online media usage. 
Finland, and Germany, the Swedish websites have nearly as many users as Austria, Finland, and Germany combined $(22.5 \%)$. With regard to awareness, two groups appear: In Austria and Germany, 20-25\% stated that they had heard of such media, whereas in Finland and Sweden, far more than half of the respondents had heard of these websites. When awareness and usage are compared, a large gap can be observed in each country. Unsurprisingly, the number of people who are aware of the existence of such websites is far greater than the number of people actually using them. The difference is especially pronounced for Finland, where the number of people who have heard of right-wing alternative online media is seven times more than the number of people using such media.

\subsection{Predictors of Right-Wing Alternative Media Consumption}

For the subsequent analyses, the data from all countries were entered into one model. The predictors of alternative media consumption were modeled using a fixedeffects binomial logistic regression. The fixed-effect ap- proach is suitable when there are country-level differences in hierarchical data, and multilevel modeling is not possible (Möhring, 2012).

The country-level differences are represented by $\mathrm{N}-1$ dummy variables, with $\mathrm{N}$ being the number of countries in the model. Dummy variables were created for Germany, Austria, and Finland, while Sweden is represented by the Intercept. The null model included only these country-level dummy variables and, thus, represents the variance in the model stemming from countrylevel differences. The Pseudo $\mathrm{R}^{2}$ values range from .01 to .08 and, thus, show that the share of variance at the country level is between $1 \%$ and $8 \%$.

Prior to the regression analyses, the data were assessed for missing values via a missing map and crosstabulations. The findings showed that only the variable political right-leaning might have been affected by a systematic nonresponse bias, since a few respondents (15.5\%) preferred not to answer the question. Furthermore, no specific outliers or individual cases that would have to be deleted were identified.

The results of the binomial logistic regression are presented in Table 3.

Table 3. Results of binomial logistic regression.

\begin{tabular}{|c|c|c|c|c|}
\hline & \multirow[b]{2}{*}{$B(S E)$} & \multicolumn{3}{|c|}{$95 \% \mathrm{Cl}$ for odds ratio } \\
\hline & & Lower & Odds ratio & Upper \\
\hline Intercept & $-1.24(0.05)^{* * *}$ & 0.12 & 0.14 & 0.17 \\
\hline \multicolumn{5}{|l|}{ Political \& Populist } \\
\hline Political Interest & $0.58(0.07)^{* * *}$ & 1.56 & 1.79 & 2.05 \\
\hline Immigration-critical & $0.57(0.06)^{* * *}$ & 1.57 & 1.78 & 2.01 \\
\hline External Efficacy & $-0.12(0.05)^{* *}$ & 0.80 & 0.89 & 0.99 \\
\hline Support of Direct Democracy & $0.01(0.05)$ & 0.91 & 1.01 & 1.12 \\
\hline Political Right-leaning & $-0.02(0.05)$ & 0.89 & 0.98 & 1.07 \\
\hline \multicolumn{5}{|l|}{ News Consumption } \\
\hline News Use Frequency & $0.18(0.05)^{* * *}$ & 1.08 & 1.20 & 1.33 \\
\hline News Interest & $0.15(0.07)^{* *}$ & 1.02 & 1.16 & 1.33 \\
\hline News Avoidance & $0.18(0.05)^{* * *}$ & 1.09 & 1.20 & 1.31 \\
\hline Social Media for News & $0.42(0.04)^{* * *}$ & 1.40 & 1.52 & 1.64 \\
\hline Social Media as Main News Source & $0.46(0.14)^{* * *}$ & 1.20 & 1.59 & 2.10 \\
\hline \multicolumn{5}{|l|}{ News Assessment } \\
\hline News Skepticism & $0.30(0.05)^{* * *}$ & 1.21 & 1.35 & 1.49 \\
\hline General Trust News & $-0.03(0.05)$ & 0.87 & 0.97 & 1.08 \\
\hline Trust PSB & $-0.51(0.07)^{* * *}$ & 0.52 & 0.60 & 0.69 \\
\hline Trust Tabloid & $0.28(0.06)^{* * *}$ & 1.18 & 1.33 & 1.49 \\
\hline Trust Legacy & $-0.14(0.07)^{*}$ & 0.76 & 0.87 & 1.01 \\
\hline \multicolumn{5}{|l|}{ Control Variables } \\
\hline Age & $-0.07(0.05)$ & 0.85 & 0.94 & 1.03 \\
\hline Gender & $0.47(0.10)^{* * *}$ & 1.32 & 1.60 & 1.94 \\
\hline DAustria & $-1.38(0.12)^{* * *}$ & 0.20 & 0.25 & 0.32 \\
\hline DFinland & $-.161(0.14)^{* * *}$ & 0.15 & 0.20 & 0.26 \\
\hline DGermany & $-1.39(0.13)^{* * *}$ & 0.19 & 0.25 & 0.32 \\
\hline
\end{tabular}

Notes: $\mathrm{R}^{2}=0.32$ (Cox \& Snell), 0.52 (Nagelkerke), 0.45 (McKelvey \& Zavoina). Model $\chi^{2}(20)=1481, \mathrm{p}<.001$.

$* \mathrm{p} \leq .05 ; * \mathrm{p} \leq .01 ; * * \mathrm{*} \leq .001$. 
In order to aid understanding, the variables were ordered according to the following underlying concepts: Political and Populist, News Consumption, News Assessment, and Control Variables. Continuous variables were z-standardized to ensure the comparability of the effect sizes and the odds ratio values. The test for multicollinearity of the variables via a calculation of the variance inflation factors presented satisfactory results (all VIF values < 3.5). Overall, a distinct improvement from model 0 to model 1 can be observed. After all the explanatory variables were included in the model, the share of variance, according to the Pseudo $R^{2}$ values, was between $32 \%$ and $52 \%$.

Figure 2 presents a visualization of the effect sizes of all significant predictors of right-wing alternative online media usage in descending order of odds ratio values (Bates, 2020; Lüdecke, 2018; RStudio, 2020).

With regard to the individual-level characteristics that predict the probability of usage of right-wing alternative online media, interest in political topics $(\mathrm{H} 1 \mathrm{a}), \mathrm{a}$ critical stance towards immigration ( $\mathrm{H} 1 \mathrm{~b}$, partially), the relevance of social media as news a source $(\mathrm{H} 2 \mathrm{c})$, a skeptical assessment of news quality in general (H3a), and lack of trust in public service broadcasting media ( $\mathrm{H} 3 \mathrm{C}$ ) emerged as the strongest predictors based on the effect sizes. In contrast, support for the sovereignty of the people (direct democracy; $\mathrm{H} 1 \mathrm{~b}$ ), as well as right-wing political attitudes $(\mathrm{H} 1 \mathrm{c})$, were not predictors of the probability of usage of alternative online news sources. Further, while a critical reflection of news, in general, could be confirmed, we did not find evidence that a general distrust in the news was predictive of alternative news consumption ( $\mathrm{H} 3 \mathrm{~b}$ ). The factor external efficacy was found to be a significant predictor of the probability of right- wing alternative online media usage. However, contrary to our expectations, the direction was reversed; this indicates a low level of support for the statement 'Most elected officials don't care what people like me think.'

\section{Discussion}

The results of the analyses above present new insights concerning two aspects of right-wing alternative online media in Northern Europe (represented by Finland and Sweden) and Central Europe (represented by Germany and Austria): (1) the general prevalence of such media and (2) the audience characteristics that explain rightwing news consumption.

The results of the prevalence of right-wing alternative online media showed a large gap between the awareness and the actual usage of these websites. The fact that approximately $20 \%$ to $53 \%$ of the respondents stated that they had heard of these websites proves a consistent presence of right-wing online media in the public discourse, probably facilitated by either traditional news websites or social media platforms. Of course, far fewer people actually use right-wing websites to inform themselves about political issues. However, the fact that supposedly small niche, hyperpartisan media are able to reach approximately $8 \%$ to $23 \%$ of people who read the news indicates that right-wing alternative online media are fairly successful in distributing their content and reaching potential audiences. For Germany, a similar survey-based study found even higher numbers for occasional usage of right-wing websites (Müller \& Schulz, 2019). The country-specific comparison of the reach points out a comparatively high popularity of rightwing online media in Sweden. In contrast, in Germany,

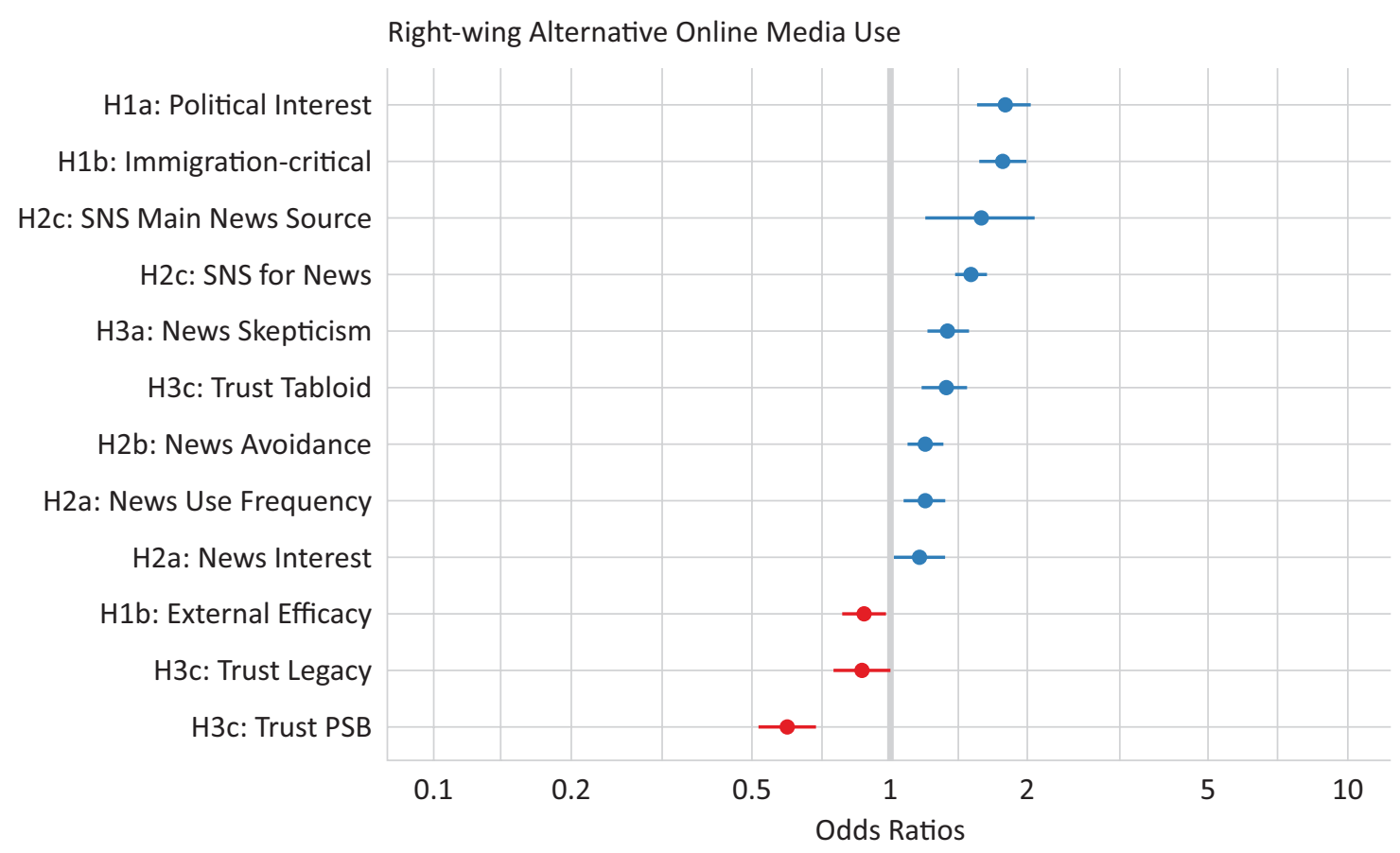

Figure 2. Odds ratio values for significant predictors. 
Austria, and Finland, these news websites seem to be less prevalent. A possible explanation for this is related to the topic of immigration: In proportion to its population, Sweden accommodated the highest number of refugees in Europe in 2015. Simultaneously, the radical right successfully framed the topic in such a way that, despite high levels of trust in media, the majority of Sweden's citizens had the impression that traditional media presented biased reporting that was considered too immigrant-friendly and instead turned to right-wing media (de La Brosse \& Thinsz, 2019). The above presented analysis of the audience characteristics corroborates the high relevance of an immigration-critical stance for rightwing alternative online media usage.

The analysis of the audience characteristics that predict the usage of right-wing alternative online media further emphasizes the significance of these websites. The results indicate that political interest, as well as a critical stance towards immigration, are the strongest predictors of right-wing alternative news use. This is supported by previous research that showed that criticism of immigrants and immigration-related policies were the central theme of right-wing media (Nygaard, 2019; von Nordheim et al., 2019). Concerning the other items that are linked to right-wing populist attitudes, the results are mixed. Neither the support for direct democracy nor right-wing political orientation seems to be relevant right-wing alternative news consumption. Müller and Schulz (2019) found that the significance of such right-wing political attitudes is directly related to the frequency of exposure to right-wing alternative news and can only be confirmed for frequent exposure, but not for occasional usage. Therefore, with regard to the present findings, it is possible that the operationalization of 'having visited a news medium within the past week' is rather representative of occasional alternative news users. With respect to the political orientation two explanations are possible: (1) The insignificance of 'rightwing attitudes' might be a result of nonresponse bias, as $15 \%$ of the respondents preferred not to answer the question concerning their political leaning; on the other hand, (2) it is plausible that alternative media are able to engage audiences also from the political center via social media platforms. It has been shown that rightwing alternative online media are very successful in distributing their content via social media (Larsson, 2019; Sandberg \& Ihlebaek, 2019), and the results of the audience characteristics indicate that using social media for news increases the likelihood of alternative online media consumption.

In addition, the results of the audience characteristics imply that a certain discontent with the general discourse driven by traditional news sources increases the likelihood of alternative online news consumption. While the difference in the predictive value of a critical reflection of news, in general (which was confirmed as a predictor) and a general distrust in the news (which was rejected as a predictor), might be a consequence of the divergent exposure to alternative news media. Possibly, the level of (dis)trust varies with respect to the intensity or frequency of consumption of alternative news. However, the more specific hypotheses concerning distrust in legacy news as well as public service broadcasting could be proven, and the results indicate that people who intentionally engage in news avoidance behavior are more likely to follow right-wing alternative online media. Similarly, trust in tabloid news, which can be linked to populist attitudes (Fawzi, 2019; Schulz, 2019), can be confirmed as a positive predictor. In fact, the heterogeneous results for news assessment are corroborated by studies from Figenschou and Ihlebæk $(2018,2019)$, who have shown that right-wing alternative media employ several dimensions of media criticism.

This study has a few limitations which have to be addressed. While the hypotheses and analyses indicate causal relationships that, to some extent, should apply, cross-sectional data are, of course, only suited to a limited extent to uncover causal mechanisms. For example, a critical stance towards traditional news media can be both the origin but also a result of these media channels. It may be the origin because distrust is one of the central reasons for skeptical producers and recipients to engage with alternative media. It may also be a result, since these media channels frequently present reasons for and thus, may initiate or reinforce media skepticism, distrust, or possibly even cynicism.

Furthermore, each large-scale cross-national survey program, such as the Reuters Digital News Survey, has limited space for items in the questionnaire. Consequently, the researcher is bound to rely on the included items for their analyses. In this case, it certainly would have been useful to have included a more comprehensive selection of alternative news websites, a more diverse elicitation of the respective consumption intensity, as well as a more established scale for populist items. For example, the anti-elite dimension, as a central element of populism, is not included in the questionnaire. Concerning the dependent variable, right-wing alternative media use, it is unclear to what extent politically more extreme and active followers of right-wing alternative media would participate in a survey such as the Reuters Digital News Survey. It is conceivable that right-wing alternative news audiences who profoundly reject the general political discourse might refuse participation in such a survey. Thus, with regard to the politically extreme members of the audience, nonresponse bias is plausible.

\section{Conclusions}

Previous research of right-wing alternative online media focused primarily on the role of content and social media distribution and paid little attention to the audiences of right-wing alternative media, especially at a cross-national level. This paper addressed this gap by exploring the prevalence of right-wing alternative online 
media, as well as the audience characteristics that explain the usage of such websites. Drawing on the 2019 Reuters Digital News Survey, this article presented a cross-national analysis of right-wing alternative online media use in Northern and Central Europe.

The results show that the prevalence of right-wing alternative online media is not alarmingly high, but high enough to conclude that they should not be underestimated or dismissed as a peripheral phenomenon. Moreover, they might have to be considered relevant actors with high mobilizing and polarizing potential (Atkinson \& Leon Berg, 2012). The fact that right-wing alternative media that do not adhere to the ruleset of traditional journalism can gain such a vast reach is cause for concern. This is especially relevant when contemplating the strongest predictors of right-wing alternative news consumption. The low level of trust in public service broadcasting media, which are occasionally perceived as government media, hints at an elite-critical stance and needs to be further studied. The finding that politically interested audiences who perceive immigration as a threat to national cultures are turning to right-wing alternative media is not surprising. After all, this is a central theme for both radical right populist parties as well as right-wing alternative online media, as previously demonstrated, especially for Northern European countries. However, the strength of this predictor, in combination with a generally skeptical assessment of traditional news sources, as well as the once again confirmed high relevance of social media platforms, call for further research into the distribution mechanisms and the media effects of right-wing alternative news content. After all, the results suggest that right-wing alternative media might function as distributors and amplifiers of immigration-critical attitudes. Altogether, the results indicate that right-wing alternative online media have to be considered influential factors for center-right to radical right-leaning politics and audiences in public discourse.

The supplementary material of this article has been uploaded to the Open Science Framework and is available via DOI, https://doi.org/10.17605/OSF.IO/ACZHF.

\section{Acknowledgments}

For their time to read and comment a draft version of this article, as well as for their feedback that helped to improve it, I would like to thank the anonymous reviewers, the editors of this thematic issue-Dr. Marlene Mauk and Prof. Jonas Linde-Sean Kates (PhD), Assistant Prof. Loes Aaldering, as well as my supervisor Prof. Diana Rieger. I am especially grateful to the Reuters Institute for the Study of Journalism at Oxford University, which conducts the Digital News Survey, as well as Dr. Sascha Hölig, who was so kind to grant me access to the data.

\section{Conflict of Interests}

The authors declare no conflict of interest.

\section{References}

Atkinson, J. D., \& Leon Berg, S. V. (2012). Narrowmobilization and Tea Party activism: A study of rightleaning alternative media. Communication Studies, 63(5), 519-535. https://doi.org/10.1080/10510974. 2011.649442

Atton, C. (2006). Far-right media on the internet: Culture, discourse and power. New Media \& Society, 8(4), 573-587.

Bachl, M. (2018). (Alternative) media sources in AfDcentered Facebook discussions. Studies in Communication and Media, 7(2), 256-270.

Bates, D., Chambers, J., Dalgaard, P., Gentleman, R., Hornik, K., Ihaka, R., . . Urbanek, S. R: A language and environment for statistical computing. $\mathrm{R}$ version 3.6.3. [Computer software]. (2020). Vienna: R Foundation for Statistical Computing. Retrieved from http://www.R-project.org

Benkler, Y., Faris, R., \& Roberts, H. (2018). Network propaganda: Manipulation, disinformation, and radicalization in American politics. New York, NY: Oxford University Press.

Brüggemann, M., Engesser, S., Büchel, F., Humprecht, E., \& Castro, L. (2014). Hallin and Mancini revisited: Four empirical types of Western media systems. Journal of Communication, 64(6), 1037-1065.

Conway, M., Scrivens, R., \& Macnair, L. (2019). Rightwing extremists' persistent online presence: History and contemporary trends. The Hague: International Center for Counter Terrorism. Retrieved from https://icct.nl/wp-content/uploads/2019/11/RightWing-Extremists-Persistent-Online-Presence.pdf

de La Brosse, R., \& Thinsz, G. (2019). Media coverage of the migratory crisis in Sweden: A revealing of the growing polarization between traditional media and antisystem media? In Ameaças ao ciberjornalismo (pp. 168-180). Porto: Universidade do Porto.

Downing, J. D. H. (2003). Audiences and readers of alternative media: The absent lure of the virtually unknown. Media, Culture \& Society, 25(5), 625-645.

Engesser, S., Fawzi, N., \& Larsson, A. O. (2017). Populist online communication: Introduction to the special issue. Information, Communication \& Society, 20(9), 1279-1292.

Farkas, J., \& Neumayer, C. (2020). Mimicking news. Nordicom Review, 41(1), 1-17.

Fawzi, N. (2019). Untrustworthy news and the media as "enemy of the people?" How a populist worldview shapes recipients' attitudes toward the media. The International Journal of Press/Politics, 24(2), 146-164.

Figenschou, T. U., \& Ihlebæk, K. A. (2018). Challenging journalistic authority. Journalism Studies, 20(9), 1221-1237.

Figenschou, T. U., \& Ihlebæk, K. A. (2019). Media criticism from the far-right: Attacking from many angles. Journalism Practice, 13(8), 901-905.

Fletcher, R. (2019). The rise of populism and the conse- 
quences for news and media use. In N. Newman, R. Fletcher, A. Kalogeropoulos, \& R. K. Nielsen (Eds.), Reuters institute digital news report 2019 (pp. 42-48). Oxford: University of Oxford

Fletcher, R., \& Park, S. (2017). The impact of trust in the news media on online news consumption and participation. Digital Journalism, 5(10), 1281-1299.

Frischlich, L., Klapproth, J., \& Brinkschulte, F. (2020). Between mainstream and alternative-Co-orientation in right-wing populist alternative news media. In C. Grimme, M. Preuss, F. W. Takes, \& A. Waldherr (Eds.), Lecture notes in computer science. Disinformation in open online media (Vol. 12021, pp. 150-167). Cham: Springer International Publishing.

Garrett, R. K. (2009). Politically motivated reinforcement seeking: Reframing the selective exposure debate. Journal of Communication, 59(4), 676-699.

Haller, A. (2018). Symbiotische Interdependenzen. Rechtspopulismus und politische Alternativpublizistik [Symbiotic interdependencies. Right-wing populism and alternative political journalism] Communicatio Socialis, 51(2), 143-153.

Haller, A., Holt, K., \& de La Brosse, R. (2019). The 'other' alternatives: Political right-wing alternative media. Journal of Alternative and Community Media. https://doi.org/10.20378/irbo-54716

Hallin, D. C., \& Mancini, P. (2004). Comparing media systems: Three models of media and politics. Communication, society and politics. Cambridge: Cambridge University Press.

Harcup, T. (2016). So many questions: What's the point of researching and teaching alternative media? Journal of Alternative and Community Media, 1(1), 19-20.

Hart, W., Albarracín, D., Eagly, A. H., Brechan, I., Lindberg, M. J., \& Merrill, L. (2009). Feeling validated versus being correct: A meta-analysis of selective exposure to information. Psychological Bulletin, 135(4), 555-588.

Heft, A., Mayerhöffer, E., Reinhardt, S., \& Knüpfer, C. (2019). Beyond Breitbart: Comparing right-wing digital news infrastructures in six Western democracies. Policy \& Internet. https://doi.org/10.1002/poi3.219

Holt, K. (2017). Completely different or versions of the same? A comparison of mainstream media (MSM) and immigration-critical alternative media (ICAM) in Sweden. Paper presented at International Communication Association (ICA), San Diego.

Holt, K. (2018). Alternative media and the notion of antisystemness: Towards an analytical framework. Media and Communication, 6(4), 49.

Holt, K. (2019). Right-wing alternative media. London and New York, NY: Routledge.

Holt, K., \& Haller, A. (2017). What does 'Lügenpresse' mean? Expressions of media distrust on PEGIDA's Facebook pages. Politik. https://doi.org/10.7146/ politik.v20i4.101534

Holt, K., Ustad Figenschou, T., \& Frischlich, L. (2019). Key dimensions of alternative news media. Digital Jour- nalism, 20(9), 1-10.

Kalogeropoulos, A., Suiter, J., Udris, L., \& Eisenegger, M. (2019). News media trust and news consumption: Factors related to trust in news in 35 countries. International Journal of Communication, 13(2019), 3672-3693.

Larsson, A. O. (2019). News use as amplification: Norwegian national, regional, and hyperpartisan media on Facebook. Journalism \& Mass Communication Quarterly, 96(3), 721-741.

Lüdecke, D. sjPlot: Data visualization for statistics in social science ( $R$ package version 2.8.4) [Computer software]. (2020). Retrieved from https://CRAN.Rproject.org/package $=$ sjPlot

Marwick, A., \& Lewis, R. (2017). Media manipulation and disinformation online. New York, NY: Data \& Society Research Institute. Retrieved from http://www.chinhnghia.com/DataAndSociety_ MediaManipulationAndDisinformationOnline.pdf

Mathes, R., \& Pfetsch, B. (1991). The role of the alternative press in the agenda-building process: Spill-over effects and media opinion leadership. European Journal of Communication, 6, 33-62.

Möhring, K. (2012). The fixed effect as an alternative to multilevel analysis for cross-national analyses. Cologne: University of Cologne.

Müller, P., \& Schulz, A. (2019). Alternative media for a populist audience? Exploring political and media use predictors of exposure to Breitbart, Sputnik, and Co. Information, Communication \& Society, 4(1), 1-17.

Newman, N., Fletcher, R., Kalogeropulos, A., Levy, D. A. L., \& Nielsen, R. K. (Eds.). (2018). Reuters institute digital news report 2018. Oxford: University of Oxford.

Newman, N., Fletcher, R., Kalogeropoulos, A., \& Nielsen, R. K. (Eds.). (2019). Reuters institute digital news report 2019. Oxford: University of Oxford.

Noppari, E., Hiltunen, I., \& Ahva, L. (2019). User profiles for populist counter-media websites in Finland. Journal of Alternative and Community Media, 4, 23-37.

Nygaard, S. (2019). The appearance of objectivity: How immigration-critical alternative media report the news. Journalism Practice, 13(10), 1147-1163.

Nygaard, S. (2020). Boundary work: Intermedia agendasetting between right-wing alternative media and professional journalism. Journalism Studies. https:// doi.org/10.1080/1461670X.2020.1722731

Otto, K., \& Köhler, A. (2016). Medienvertrauen auf dem Tiefpunkt? [Trust in media at all-time low?]. European Journalism Observatory. Retrieved from http:// de.ejo-online.eu/qualitaet-ethik/medienvertrauenauf-dem-tiefpunkt

Puschmann, C., Ausserhofer, J., Maan, N., \& Hametner, M. (2016). Information laundering and counterpublics: The news sources of islamophobic groups on twitter. Presented at The Workshops of the Tenth International AAAI Conference on Web and Social Media, Cologne.

Rauch, J. (2007). Activists as interpretive communities: 
Rituals of consumption and interaction in an alternative media audience. Media, Culture \& Society, 29(6), 994-1013.

Rauch, J. (2015). Exploring the alternative-mainstream dialectic: what "alternative media" means to a hybrid audience. Communication, Culture \& Critique, 8(1), 124-143.

Rauch, J. (2019). Comparing progressive and conservative audiences for alternative media and their attitudes towards journalism. In J. D. Atkinson \& L. J. Kenix (Eds.), Alternative media meets mainstream politics: Activist nation rising (pp. 19-38). Lanham, MD: Lexington Books.

RStudio. RStudio: Integrated Development for R. [Computer software]. (2020). Boston, MA: RStudio. Retrieved from http://www.rstudio.com

Sandberg, L. A. C., \& Ihlebaek, K. A. (2019). Start sharing the news: Exploring the link between right-wing alternative media and social media during the Swedish 2018 election. Statsvetenskaplig Tidskrift, 121(3), 421-440.

Schindler, J., Fortkord, C., Posthumus, L., Obermaier, M., \& Reinemann, C. (2018). Woher kommt und wozu führt Medienfeindlichkeit? Zum Zusammenhang von populistischen Einstellungen, Medienfeindlichkeit, negativen Emotionen und Partizipation [Where does media hostility come from and what does it lead to? The connection between populist attitudes, media hostility, negative emotions and participation]. Medien \& Kommunikationswissenschaft, 66(3), 283-301.

Schulz, A. (2019). Where populist citizens get the news: An investigation of news audience polarization along populist attitudes in 11 countries. Communication Monographs, 86(1), 88-111.

Schulze, H., \& Hölig, S. (2020). Die Nachrichtenmediennutzung von Rezipienten rechter, alternativer Nachrichtenwebsites: Ein netzwerkanalytischer Ansatz zur Visualisierung der Audience Overlaps [News media consumption of recipients of right-wing, alternative news websites: A network analytical approach to the visualization of audience overlaps]. Munich: Jahrestagung der Deutschen Gesellschaft für Publizistik-Und Kommunikationswissenschaft.

Starbird, K. (2017). Examining the alternative media ecosystem through the production of alternative narratives of mass shooting events on Twitter. Paper presented ate Tenth International Conference on Web and Social Media (ICWSM), Montreal, Canada.

Stier, S., Kirkizh, N., Froio, C., \& Schroeder, R. (2020). Populist attitudes and selective exposure to online news: A cross-country analysis combining web tracking and surveys. The International Journal of Press/Politics. https://doi.org/10.1177/1940161220907018

Strömbäck, J., Djerf-Pierre, M., \& Shehata, A. (2013). The dynamics of political interest and news media consumption: A longitudinal perspective. European Journal of Political Research, 25(4), 414-435.

Tsfati, Y., \& Cappella, J. N. (2003). Do people watch what they do not trust? Exploring the association between news media skepticism and exposure. Communication Research, 30(5), 504-529.

Tsfati, Y., \& Peri, Y. (2006). Mainstream media skepticism and exposure to sectorial and extranational news media: The case of Israel. Mass Communication and Society, 9(2), 165-187.

Tucker, J., Guess, A., Barberá, P., Vaccari, C., Siegel, A., Sanovich, S., . . . Nyhan, B. (2018). Social media, political polarization, and political disinformation: $A$ review of the scientific literature. SSRN Electronic Journal. Advance online publication. https://doi.org/ 10.2139/ssrn.3144139

von Nordheim, G., Müller, H., \& Scheppe, M. (2019). Young, free and biased: A comparison of mainstream and right-wing media coverage of the 2015-16 refugee crisis in German newspapers. Journal of Alternative and Community Media, 4, 38-56.

Ylä-Anttila, T. (2018). Populist knowledge: 'Post-truth' repertoires of contesting epistemic authorities. European Journal of Cultural and Political Sociology, 5(4), 356-388.

\section{About the Author}

Heidi Schulze is a Doctoral Researcher at the Department of Media and Communication at LMU Munich (Germany) and a Research Associate at GESIS-Leibniz Institute for the Social Sciences. At LMU, she is part of the Research Lab of Prof. Dr. Rieger and works in an interdisciplinary research project on online radicalization employing computational methods. In her thesis, Ms. Schulze studies characteristics and audiences of alternative online media and hyperpartisan news websites. 